\title{
Clinical Analysis and Perinatal Outcome in Pregnant Patients with COVID-19
}

\author{
Saima Najam¹, Sumaiyya Ejaz Malik², Syeda Ifra Hassan³, \\ Mohammed Mubarak Ahmed ${ }^{4}$, Adiba Shireen ${ }^{5}$ \\ ${ }^{1}$ FCPS, PG Certification in Medical Education (Dundee), Head of the OBGYN Department, \\ Dr. Sulaiman Al Habib Hospital, Sweidi, Riyadh, Saudi Arabia \\ ${ }^{2}$ MRCOG, Specialist, OBGYN, Dr. Sulaiman Al Habib Hospital, Sweidi, Riyadh, Saudi Arabia \\ ${ }^{3}$ Voluntary Worker, Student of IGSCE, Manarat Alriyadh International School, Riyadh \\ ${ }^{4}$ Consultant Neonatologist, Dr. Sulaiman Al Habib Hospital, Sweidi, Riyadh, Saudi Arabia \\ ${ }^{5}$ MRCOG, Specialist, OBGYN, Dr. Sulaiman Al Habib Hospital, Sweidi, Riyadh, Saudi Arabia
}

Corresponding Author: Saima Najam

\begin{abstract}
Background: Severe acute respiratory syndrome Corona virus 2 (SARS-CoV-2) is the felon responsible for the extraordinary global pandemic of COVID-19 disease. As per the world health organization WHO) updates dated $12^{\text {th }}$ April 2021 the total number of cases worldwide were 135,6,46,617 out of which 399,277 were reported in Saudi Arabia, as the number of the Covid patients is increased, the number of pregnant patients effected by the disease are also increasing. We therefore planned this study to do the clinical analysis of the pregnant patients with COVID-19 and to see the effect of the disease on the perinatal outcome.

Objective: The purpose of the study was to prove the null hypothesis that perinatal morbidity is increased with severity of the Covid 19 effected pregnant patients.

Material and Methods: It was a prospective observational study. All the patients who presented at term in labor with singleton pregnancy and with positive nasopharyngeal swab in last 10 days were included in the trial. While the women who had Preterm labor, multiple pregnancy and any other medical disorder were excluded from the study. The duration of the study was 6 months (01/09/202028/02/2021) and was conducted in the labor ward of Dr. Sulaiman Al Habib Hospital, Sweidi, Riyadh, Saudi Arabia.

Results: The total numbers of patients enrolled to the trial were 45 . The $73 \%$ of the study population presented with mild symptoms $(\mathrm{n}=33)$ and moderate and severe symptoms were observed in $22.2 \%$ $(n=10)$ and $4.4 \%(n=2)$ of the population respectively. The 5-minute Apgar score was compared in three groups and was found significantly lower in patients having moderate and severe Covid symptoms (P-value was 0.003). However, the difference in cord $\mathrm{pH}$ and NICU (neonatal intensive care unit) admission was not found statistically significant. No risk of the vertical transmission was found when calculated by doing the neonatal swab within 24 hours. The prevalence of Cesarean section was higher in patients having moderate and severe symptoms, though the difference was not found statistically significant. Female gender prevalence was observed in patients having moderate symptoms $(70 \%, \mathrm{n}=07)$.
\end{abstract}

Conclusion: On the basis of our observations we hereby reject our hypothesis that the perinatal morbidity is increased in patients having moderate or severe Covid symptoms.

Key words: Pregnancy, labour, Covid-19, neonate, vertical transmission, mode of delivery

\section{INTRODUCTION}

Severe acute respiratory syndrome Corona virus 2 (SARS-CoV-2) is the felon responsible for the extraordinary global pandemic of COVID-19 disease. As per the world health organization WHO) updates 
dated $12^{\text {th }}$ April 2021 the total number of cases worldwide were $135,6,46,617$ out of which 399,277 were reported in Saudi Arabia, ${ }^{(1)}$ as the number of the Covid patients is increased, the number of pregnant patients effected by the disease are also increasing. The physiological changes in the pregnancy increases the susceptibility of the pregnant patient to severe respiratory infections and subsequent respiratory failure which is a key concern in these patients. ${ }^{(2)}$ Maternal respiratory problems inevitably increase the risk of hypoxic injury to the fetus. Pregnancy also alters the body's immune system and response to viral infections in general, which can occasionally cause more severe symptoms. This may be the same for COVID-19 but there is currently no evidence that pregnant women are more likely to be severely unwell needing admission to intensive care or die from the illness than non-pregnant adults. ${ }^{(3)}$

We therefore planned this study to do the clinical analysis of the pregnant patients with COVID-19 and to see the effect of the disease on the perinatal outcome.

The purpose of the study was to prove the null hypothesis that perinatal morbidity is increased in pregnant patients with severity of the Covid 19. Primary outcome is Apgar score, admission to the neonatal intensive care unit and vertical transmission.

Secondary outcome is mode of delivery and gender prevalence.

\section{MATERIAL AND METHODS} study.

It was a prospective observational

All the patients who presented at term in labor with singleton pregnancy and with positive nasopharyngeal swab for Covid in last 10 days were included in the trial. While the women who had Preterm labor, multiple pregnancy and any other medical disorder were excluded from the study. The duration of the study was 6 months (01/09/2020- 28/02/2021) and was conducted in the labor ward of Dr. Sulaiman Al Habib Hospital, Sweidi, Riyadh, Saudi Arabia, which is a 350 bedded multidisciplinary hospital.

The patients once enrolled to the trial were divided in to three groups depending upon their symptoms i.e mild moderate and severe. Patients with fever, flu, anosmia, myalgia, diarrhea etc, in the absence of oxygen dependency were considered as having mild disease. If they require oxygen then they were included in the moderate disease group. All the patients who required more than 15 liters of oxygen or ventilatory support or having multiple organ failure were included in the severe disease group.

The data was collected with the help of the predesigned proforma prospectively. Once the data is collected it is entered in SPSS program version 26 for the analysis. The primary and the secondary outcome are compared among the three groups.

The qualitative data was analyzed by using the Chi-square Test while student $t$ test was applied to the quantitative data. The $\mathrm{P}$-value of 0.05 or less was considered as significant.

\section{RESULTS}

The total numbers of patients enrolled to the trial were 45 . The $73 \%$ of the study population presented with mild symptoms $(n=33)$ and moderate and severe symptoms were observed in $22.2 \%(n=10)$ and $4.4 \% \quad(n=2)$ of the population respectively.

The mean age of the patients presented with the Covid symptoms was 30.3 years irrespective of the severity of the symptoms, with standard deviation of 4.5. The nulliparous and the primiparous women were observed to have mild symptoms while the patients who were multipara (para 3 and above) were found to have severe symptoms though the difference was not found statistically significant ( $\mathrm{P}$ - value is 0.2 , after applying the chi-square test). As $91 \%$ of the study population was Saudi, so no 
significant effect of ethnicity on Covid symptoms could be concluded.

The 5-minute Apgar score was compared in three groups and was found lower in patients having moderate and severe Covid symptoms as shown in table 1 .
The difference was found statistically significant as the P-value was 0.003 when calculated after applying the Independent T-test.

Table 1: The relationship of the APGAR score and the Covid symptoms.

\begin{tabular}{|l|l|l|l|l|}
\hline $\begin{array}{l}\text { APGAR SCORE } \\
\text { After 5 minutes }\end{array}$ & MILD COVID SYMPTOMS & $\begin{array}{l}\text { MODERATE } \\
\text { COVID SYMPTOMS }\end{array}$ & $\begin{array}{l}\text { SEVERE } \\
\text { COVID SYMPTOMS }\end{array}$ & \\
\hline 5 & $0.00 \%(\mathrm{n}=0)$ & $10 \%(\mathrm{n}=01)$ & $0.00 \%(\mathrm{n}=00)$ & $2.22 \%(\mathrm{n}=01)$ \\
\hline 7 & $3.03 \%(\mathrm{n}=01)$ & $00 \%(\mathrm{n}=00)$ & $100 \%(\mathrm{n}=02)$ & $6.66 \%(\mathrm{n}=03)$ \\
\hline 8 & $15.1 \%(\mathrm{n}=05)$ & $10 \%(\mathrm{n}=01)$ & $00.0 \%(\mathrm{n}=00)$ & $13.3 \%(\mathrm{n}=06)$ \\
\hline 9 & $81.8(\mathrm{n}=27)$ & $80 \%(\mathrm{n}=08)$ & $00.0 \%(\mathrm{n}=00)$ & $77.7 \%(\mathrm{n}=35)$ \\
\hline & $73.3 \% \mathrm{n}=33)$ & $22.2 \%(\mathrm{n}=10)$ & $4.44 \%(\mathrm{n}=02)$ & $100 \%(\mathrm{n}=45)$ \\
\hline
\end{tabular}

The difference in the cord blood $\mathrm{pH}$ was not found significantly different among the groups. The mean $\mathrm{pH}$ was 7.25. (P-value $0.124)$.

The $39 \% \quad(n=13)$ of the neonates delivered to the mothers having mild Covid symptoms were admitted in neonatal intensive care unit (NICU ) while $70 \%(\mathrm{n}=7)$ and $50 \%(\mathrm{n}=1)$ of the newborns delivered to mothers with moderate and severe Covid symptoms were admitted in NICU respectively.

But the difference is found statistically insignificant as the P-value was 0.235 after applying the Chi-square test, as shown in figure 1.

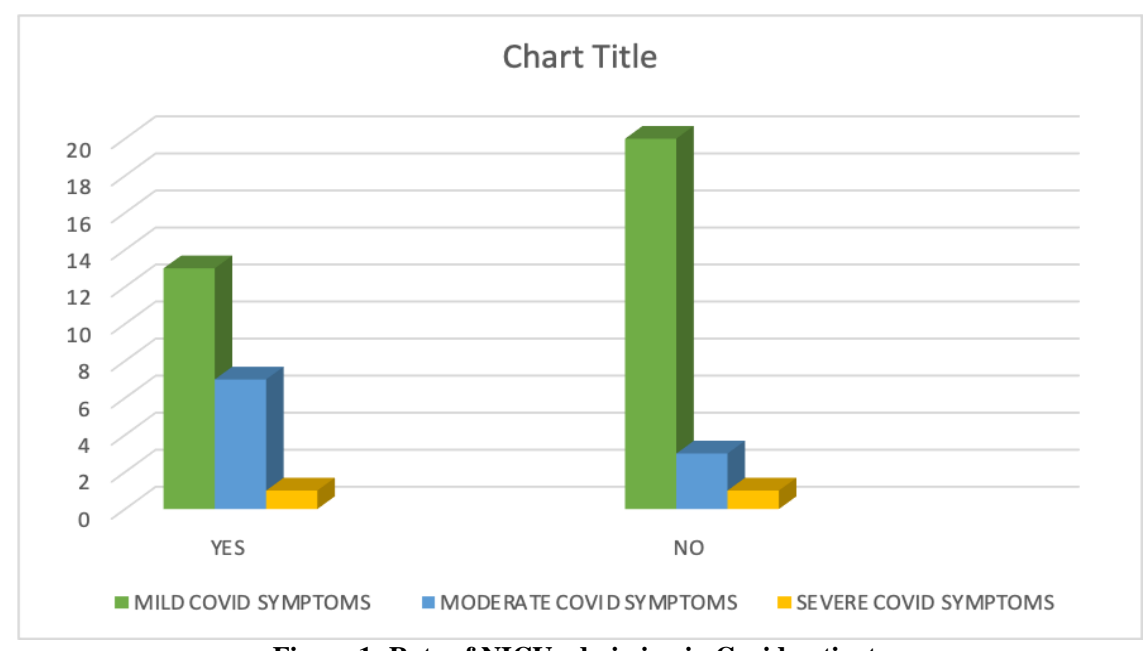

Figure 1: Rate of NICU admission in Covid patients

To check the vertical transmission to the neonate, the swab of the neonate was done after taking consent from the patient, $57.5 \%(\mathrm{n}=19)$ of the patients having the mild symptoms refused for the neonatal swab. The neonatal swab was done in $42 \%$ $(n=14)$ of the patients having mild symptoms and it was done $100 \%$ in patients having moderate $(\mathrm{n}=10)$ and severe symptoms $(\mathrm{n}=02)$ respectively. All the neonatal swabs were done within first 24 hours of the birth and not a single swab was found positive.

Table 2: Effect of severity of the Covid on mode of delivery.

\begin{tabular}{|l|l|l|l|l|}
\hline MODE OF DELIVERY & MILD COVID SYMPTOMS & $\begin{array}{l}\text { MODERATE } \\
\text { COVID SYMPTOMS }\end{array}$ & $\begin{array}{l}\text { SEVERE } \\
\text { COVID SYMPTOMS }\end{array}$ & TOTAL \\
\hline SVD & $60.6 \%(\mathrm{n}=20)$ & $30 \%(\mathrm{n}=03)$ & $50 \%(\mathrm{n}=01)$ & $53.3 \%(\mathrm{n}=24)$ \\
\hline LSCS & $39.4 \%(\mathrm{n}=13)$ & $60 \%(\mathrm{n}=06)$ & $50 \%(\mathrm{n}=01)$ & $44.4 \%(\mathrm{n}=20)$ \\
\hline KIWI & $00.0 \%(\mathrm{n}=0)$ & $10 \%(\mathrm{n}=01)$ & $00.0 \%(\mathrm{n}=00)$ & $2.2 \%(\mathrm{n}=01)$ \\
\hline TOTAL & $73.3 \%(\mathrm{n}=33)$ & $22.2 \%(\mathrm{n}=10)$ & $4.44 \%(\mathrm{n}=02)$ & $100 \%(\mathrm{n}=45)$ \\
\hline
\end{tabular}


The relationship of the mode of the delivery and the Covid symptoms is shown in Table-2. However, the difference was found statistically insignificant as the Pvalue calculated after applying the chisquare test was 0.395 .

Female babies were delivered by $70 \%(n=7)$ of the patients having moderate and $50 \%(\mathrm{n}=1)$ of the patients having severe symptoms. while the ratio of male and female babies in the patients with mild symptoms was $49 \%(\mathrm{n}=16)$ and $51 \%(\mathrm{n}=17)$ respectively, as shown in figure 2 . The difference was insignificant as the P-value is 0.58 .

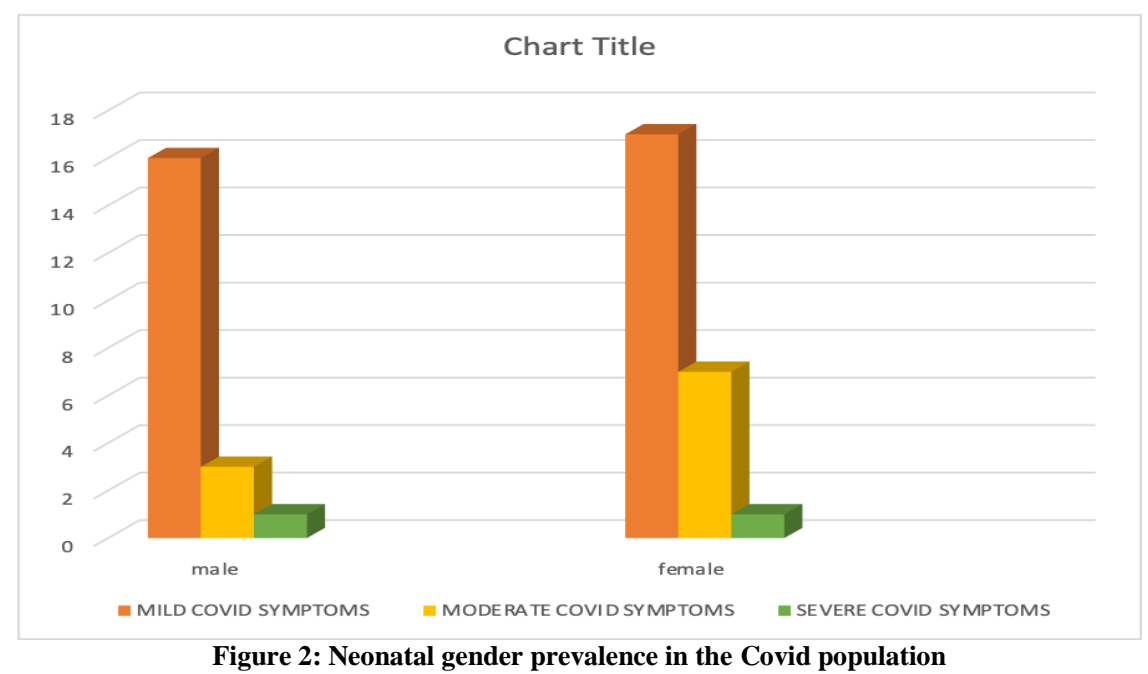

\section{DISCUSSION}

It is assumed that the Covid 19 pregnant women follow the same course of disease as non pregnant and are more susceptible to the respiratory and thrombotic complications due to the physiological changes in the pregnancy. Covid-19 infection is associated with maternal pyrexia, cytokine storm and hypercoagulability, which increases the risk of placental inter villous thrombosis and infarction as well as maternal hypoxia secondary to adult respiratory syndrome. ${ }^{(4)}$

It was found in the current study that the majority of the pregnant patients had mild symptoms of the Covid. This was supported by the evidence collected by Smith V et al who suggested that there is little evidence that the Covid 19 leads to severe disease in pregnant patients. (2) Similarly Ayed and colleagues in Kuwait in their study with 185 infected pregnant patients also found that the majority of the infected pregnant women had mild symptoms only. ${ }^{(5)}$ The systemic review done by Zaigham $\mathrm{M}$ and Anderson also verified our findings as they observed that majority of the pregnant patients had mild symptoms. ${ }^{(6)}$ This was in contrary to what the Centers for Disease Control and Prevention surveillance report found. They found that the pregnant women are more likely to be admitted in ICU and receive mechanical ventilation. ${ }^{(7)}$

Although there is no evidence to suggest that Covid -19 has a direct effect on fetal morbidity and mortality. (3) We assumed that the Covid 19 mothers have high risk of perinatal morbidity and mortality. This could be due to the increased incidence of fetal heart rate changes detected on cardiotocography. (8) The increased fetal distress manifested by the cardiotocographic abnormalities or the meconium stained liquor can increase the rate of NICU admission and the risk of having low APGAR score, which will increase the perinatal morbidity, but the available data is still inconclusive regarding this issue as well. ${ }^{(9)}$

In the current study, the 5-minute Apgar score when compared in three study 
groups was found significantly lower in patients having moderate and severe Covid symptoms, However, the difference in cord $\mathrm{PH}$ and NICU admission was not found statistically significant. This was supported by Bonfils and colleagues who found absence of the metabolic acidosis in these neonates, however they observed the normal five minute Apgar score in the babies born to the Covid patients which was contrary to our results. ${ }^{(8)}$

Similar results were found in another study in which the majority of neonates born to mothers with confirmed SARSCoV-2 infection were found asymptomatic and discharged home well. Only a small number of neonates had symptoms with a minority requiring admission to neonatal specialist care. ${ }^{(10,11)}$ The study results were supported by the meta analysis done by Chmielewska et al, as they observed no increase in the NICU admission. ${ }^{(12)}$

The current study showed that there is no risk of the vertical transmission as all the nasopharyngeal swabs of the neonates done within 24 hours of delivery were negative. The study results were supported by Wang $\mathrm{C}$ who found $\mathrm{n}$ no concrete evidence of intrauterine vertical transmission associated with the disease. ${ }^{(13)}$ The two earlier studies done in pregnant patients with Covid 19 in third trimester also backed up our results as no evidence of vertical transmission was found by them, when they tested amniotic fluid and cord blood in addition to the neonatal throat swab. (14, 15) Though due to the limited resources neonatal nasopharyngeal swab was tested only in the current study however in other studies in which PCR testing of placenta, amniotic fluid, cord blood or breast milk samples were tested, no evidence of the vertical transmission was suggested. $(16,17)$

It was observed in the current study that the rate of cesarean section is higher in patients with moderate and severe symptoms; the same finding was observed by Karimi et al in their meta-analysis. ${ }^{(18)}$ However Villar $\mathbf{J}$ and colleagues observed high rate of caesarean section in Covid patients irrespective of the severity if the disease. ${ }^{(19)}$

It was found that the patients having the male babies were more prone to develop moderate symptoms, while their chance of having mild and severe symptoms were equal if effected by the Covid-19 during pregnancy.

\section{Strengths and weaknesses of the study:}

The strength of the study is that the effect of the Covid on perinatal outcome is observed in terms of the severity of the symptoms. In the current study only the nasopharyngeal swab was done once within 24 hours to rule out the vertical transmission, Another study including PCR testing for SARS-CoV-2 in cord blood, placental tissue, amniotic fluid and amnion chorion swab supplemented by the serological tests and the longitudinal followup of the neonates for 6-18 months is required to help clarify the question of the vertical transmission of the SARS-CoV-2.

\section{CONCLUSION}

On the basis of the observations of the current study it is concluded that the majority of the pregnant patients who were infected with Covid presented with mild symptoms, for the patients who had moderate or severe disease the increased risk of cesarean delivery was observed in them. It was also found that having female gender will predispose the women to develop moderate symptoms, though the difference was found statistically insignificant. We hereby reject our hypothesis that the perinatal morbidity is increased in patients having moderate or severe Covid symptoms.

\section{ACKNOWLEDGMENT}

The authors want to acknowledge the cooperation of the infection control team and all the nurses and the residents of the labor ward and the nursery for their cooperation and support in collecting data. 
Conflict of Interest: None

\section{Source of Funding: None}

Ethical Approval: Approved

\section{REFERENCES}

1. Weekly operational update on COVID19.2021.Issue no.50. World Health Organization.

2. Smith V, Seo D,Warty R, Payne O, Salih $\mathrm{M}$, Chin KL, etal. Maternal and neonatal outcomes associated with Covid 19 infection: A systemic review. PLoS ONE: 2020 June 4 ; cited 2021 Feb 14.Available fromhttp://doi.org/10.1371/journal.pone.0 234187.

3. Favre G, Pomar L, Musso D, Baud D. 2019-nCoV epidemic: what about pregnancies? The Lancet .2020 February 06; cited 2021 March 03. Available from https://doi.org/10.1016/S01406736(20)30311-1.

4. Huang C, Wang Y, Li X, Ren L, Zhao J, $\mathrm{Hu} \mathrm{Y}$, et al. Clinical features of the patients infected with 2019 novel coronavirus in Wuhan, China. Lancet, 2020;395(10223):497-506.

5. Ayad A, Embaireeg A, Benewadh A, AlFouzan W, Hammoud M, Al-Hathal M, etal. Maternal and perinatal characteristics and outcomes of pregnancies complicated with COVID -19 in Kuwait. BMC Pregnancy and Childbirth. 2020;20:75462.

6. Zaigham M, Anderson O. Maternal and perinatal outcomes with Covid-19: Asystemic review of 108 pregnancies. Acta Obstet Gynecol Scand.2020; 99(7):823-9.

7. Ellington S, Strid P, Tong T, Woodworth $\mathrm{K}$, Galan RR, Zambrano LD, et al. Characteristics of women of reproductive age with laboratory-confirmed SARS-Co V-2 infection by pregnancy status. Morbidity and mortality weekly report. 2020; 69(25):769-75.

8. Bonfil AGP, Perez OM, Llurba E, Chandraharan E. Fetal heart rate changes on the cardiotocograph trace secondary to maternal Covid-19 infection. European Journal of Obstet and Gynecol and Reprod
Bio 252. 2020 June 25; cited 2021 March 06. Available from http://doi.org/10.1016/j.ejorgrb.2020.06.0 49

9. Juan J, Gil MM, Rong Z, Zhang Y, Zhang $\mathrm{H}$, Poon LC. Effect of corona virus disease 2019(Covid-19) on maternal perinatal and neonatal outcome: systemic review. Ultrasound Obstet Gynecol. 2020;56:15-27.

10. Zhu H, Wang L, Fang C, Peng S, Zhang $L$,hang $G$,et al. Clinical analysis of 10 neonates born to mothers with 2019-nCoV pneumonia. Transl Pediat. 2020;9(1):5160.

11. Breslin N, Baptiste C, Gyamfi-Bannerman C, Miller R,Martinez R,Bernstein K, et al. COVID-19 infection among asymptomatic and symptomatic pregnant women: Two weeks of confirmed presentations to an affiliated pair of New York City hospitals. AJOGMF.2020 May 01;cited 2021 April 13. Available from http://doi.org/10.1016/j.ajogmf.2020.1001 18

12. Chmielewska B, Barratt I, Townsend R, Kalafat E, Meulen JVD, Urganci IG, etal. Effects of COVID-19 pandemic on maternal and perinatal outcomes: a systemic review and meta-analysis. Lancet Glob Health .2021 March 31; cited 2021 May 05. Available from http://doi.org/10.1016/52214$109 \times(21) 00079-6$.

13. Wang C, Zhou YH,Yang HX, Poon LC. Intrauterine vertical transmissionof SARS-Cov-2: what we know so far. Ultrasound Obstet Gynecol .2020;55:7245.

14. Chen H, Guo J, Wang C, Luo F, Yu X, Zhang W, etal. Clinical characteristics and intra uterine vertical transmission potential of Covid-19 infection in nine pregnant women : A retrospective review of medical records. Lancet. 2020;395:809815.

15. Lei D, Wang C, Li C, Fang C, Yang W, Cheng B, etal. Clinical characteristics of covid -19 in pregnancy : analysis of nine cases. Chin J Perinat Med. 2020;23:22531. 
16. Lamouroux A, Attie-Bitach T, Martinovic J, Leruez-Ville M, Ville Y. Evidence for and against vertical transmission for SARS-CoV-2 (COVID-19). Am J obstet Gynecol. 2020;91-4.

17. Martins-Filho PR, Santos VS, Santos HP, Jr. To breastfeed or not to breastfeed? Lack of evidence on the presence of SARS-CoV-2 in breastmilk of pregnant women with COVID-19. Rev Panam Salud Publica. 2020;44:1-5.

18. Karimi L, Makvandi S, Azimi AV, Sathyapalan T, Sahebkar A. Effect of Covid 19 on mortality of pregnant and postpartum women: A systemic review and meta-analysis. Journal of pregnancy.2021 March 08; cited on 2021
May 03. Available from http://doi.org/10.1155/2021/8870129.

19. Villar J, Ariff S, Gunier RB, Thiruvengadam R, Rauch S, Kholin A, etal. Maternal and neonatal morbidity and mortality among pregnant women with and without covid-19 infection. The intercovid multinational cohort study. JAMA Pediatr,. 2021 April 22; cited on 2021 May 17. Available from http://jamanetwork.com

How to cite this article: Najam S, Malik SE, Hassan SI et.al. Clinical analysis and perinatal outcome in pregnant patients with COVID-19. Int J Health Sci Res. 2021; 11(6): 72-78. DOI: https://doi.org/10.52403/ijhsr.20210611 